\title{
Locational Aspects of Industrial Ecology and Experiences of Practitioners from a Hungarian Industrial Park
}

\author{
By Noémi Csigéné Nagypál ${ }^{1}$
}

\begin{abstract}
The present article aims to contribute to understanding the relationship between the concepts of industrial ecology and circular economy in order to foster circular economy attempts. While research mostly focuses on various forms of industrial ecology or innovative technologies, it is also reasonable to analyse some mature industrial ecology practices, which can be used as quasi-models for circular economy. The technology selected for this study is flue gas desulphurisation in fossil fuel power plants and the utilization of gypsum produced in this process as a by-product by construction sector companies. In the first part of our article we briefly present the concept of industrial ecology and discuss its applicability as a potential model for circular economy as well as its locational aspects. Afterwards based on a literature review and stakeholder interviews a Hungarian power plant and industrial park is presented as a case study. The relevance of criteria of ecoinnovation parks are presented for the selected industrial park as well as the experience of industrial ecology by participating companies. Finally some general conclusions, based on the literature and the case study, are also discussed.
\end{abstract}

Keywords: industrial ecology, locational aspects, industrial park, FGD gypsum

\section{Introduction}

The concept of industrial ecology was first proposed in the late 1980s (Frosch \& Gallopoulos, 1989) and became commonly known during the 1990s. The term was not unknown before, but its meaning in economic geography was different, not related to environmental performance, referring only to the practicality of locating companies/activities using each other's products as inputs in close proximity (Renner, 1947). The basic idea of the term as it is widely applied now is that - as with the growing size of the economy, both the amount of resources exploited and the waste generated are growing - industrial production should be transformed and become more similar to ecological processes. This would primarily mean closing material flows and reducing the amount of energy input by saving energy, e.g. by energy cascading (Frosch \& Gallopoulos, 1989). Thus, certain flows of energy and materials define the industrial ecology system. Additionally, in case of a properly managed system, information is also shared by participants in a conscious and effective way. Therefore, information flow can be considered as the third essential type of flows in industrial ecosystems, in an ideal case, helping the optimisation of other flows. The role of information is discussed by Allenby (Allenby, 2004) in a wider context, providing a conceptual approach on the relation of these three types of flows, concluding that the increasing importance of 
information does not only influence production in a direct way, but also indirectly, by influencing the whole socio-cultural context (Allenby, 2004).

\section{Industrial Ecology as a Potential Model of Circular Economy}

In order to realise circular economy objectives (European Commission, 2014) it is useful to investigate industrial ecology practices or existing industrial ecosystems. Industrial ecosystems are dissimilar from natural ecosystems from various aspects. The main difference is that their main purpose is not internal, but providing products for external consumers. The controlled nature of the system is also a major difference: for ecosystems controllability is not expected, the evolution of flows was not intentional and pre-planned, the system evolved in a spontaneous way and its long-term sustainability is neither targeted nor guaranteed. In case of industrial ecosystems, controllability is highly expected.

Industrial ecology is not the only concept "borrowed" from nature to describe desirable industrial processes. Industrial symbiosis (IS) is a similar term, introduced by Lowe and Evans (Lowe \& Evans, 1995) based on observations that in some industrial complexes different industries spontaneously exchanged material flows on a large scale. The term industrial symbiosis is emphasising the interdependence of the actors and the presence of mutual benefits, win-win situations (Boons et al. 2011). IS is considered as an innovative way to increase resource productivity (European Commission, 2011).

Similarly, some terms originally developed in economic theory nowadays are frequently used to describe some phenomena of nature. The main intention is to make decisionmakers - who typically prefer economic considerations - familiar with the importance of nature (ecosystems) and the services/benefits it provides. The term natural capital is widely used in recent EU environmental policy, for example, the $7^{\text {th }}$ Environmental Action Program attempts "to protect, conserve and enhance the Union's natural capital" (EU, 2013, p. 174). The systematic assessment of ecosystem services, boosted by the United Nations Millennium Ecosystem Assessment has accumulated immense knowledge about the types, state and value of various ecosystem services worldwide.

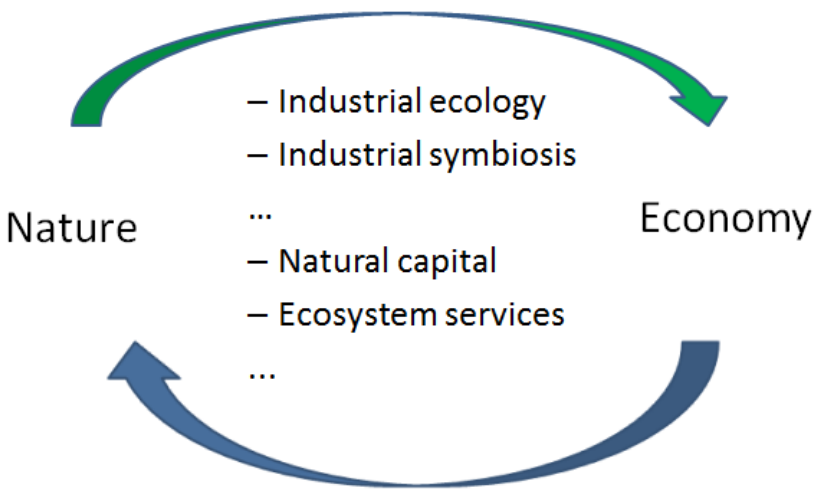

Figure 1: Terms "borrowed" from nature to describe economic phenomena and vica versa Source: own compilation 
Regarding the relationship of "nature" or ecosystem and the economy, the concept of "hybrid human and natural systems" proposed by Allenby's (Allenby, 1998) work on the concept of earth systems engineering suggests that nowadays it is very difficult to distinguish or separate the two, because of the widespread interactions. Landscape ecology is a useful related approach, since man-made systems have partly co-evolved with natural ones, therefore "it is very difficult to separate the human industrial, residential or urban infrastructural systems from natural ecosystems" (Korhonen et al., 2004, p. 805.) and in many regions nature in its original state cannot be found and preserved anymore. Landscape ecology has a strong sustainable regional development relevance, too, as according to this approach the environment is seen as a "mosaic" or "mixture" of natural and urban units and it targets management issues of the territory while typically focus on a time span of one or two generations (Yang \& Lay, 2004).

Industrial ecology practices can serve as a potential model for circular economy from various aspects. (1) The number of partners is limited. (2) In several cases the types of actors involved also make IE proper to analyse the potentials of circular economy. In many cases the cooperation is not limited to companies, but public actors, typically municipalities or regional development organisations also participate (e.g. in the prominent case of Kalundborg, Denmark) (Frosch \& Gallopoulos, 1989). Universities, research institutes and consultants are also typical potential contributors. Therefore successful industrial ecology practices are not only useful to analyse material and energy flows from an engineering point of view, but the behaviour of various participants can also be observed and analysed from a social scientific approach.

Industrial ecology can be viewed as a model for circular economy as it has several features of a well-functioning model, including scale, relatively low level of complexity and high controllability. Since the main purpose is not modelling, but the realisation of economic and environmental benefits for participants, we cannot explicitly use them as models, e.g. by implementing well-planned experiments. However, as several cases are available with various circumstances and development paths, a lot of information has accumulated, making IE systems "quasi-models" of a circular economy.

Korhonen (Korhonen, 2005) discusses the relevance and usefulness of the concept of diversity for industrial ecology. He also concludes that while engineering aspects are dominant when analysing IE, they should be supplemented by social scientific issues (Korhonen, 2005). Investigating existing IE practices can be useful for this purpose, too. The following table compares the two concepts, industrial ecology and circular economy, regarding the type and number of actors, locality, product and optimisation focus. Although industrial ecology focuses on the production phase, in some cases consumers can also be involved in the processes to some extent, e.g. Massard et al. mention "mixed urban and industrial areas" (Massard et al., 2014) when analysing ecoinnovation parks. 
Table 1: Comparison of industrial ecology and circular economy

\begin{tabular}{|l|l|l|}
\hline & Industrial ecology & Circular economy \\
\hline Type of actors & $\begin{array}{l}\text { Producers, service providers, } \\
\text { municipalities, regulator, academic } \\
\text { sector... }\end{array}$ & $\begin{array}{l}\text { Producers, service providers, policy } \\
\text { makers, municipalities, academic sector, }+ \\
\text { consumers }\end{array}$ \\
\hline $\begin{array}{l}\text { Number of } \\
\text { actors }\end{array}$ & Limited & Multiple \\
\hline Locality & $\begin{array}{l}\text { Typically geographically } \\
\text { concentrated, local or regional }\end{array}$ & $\begin{array}{l}\text { National, macro-regional (e.g. EU) or } \\
\text { global focus }\end{array}$ \\
\hline Product focus & Raw materials, by-products & $\begin{array}{l}\text { Raw materials, by-products + end-of-life } \\
\text { consumer products }\end{array}$ \\
\hline $\begin{array}{l}\text { Focus of } \\
\text { optimisation }\end{array}$ & $\begin{array}{l}\text { Economic and environmental } \\
\text { efficiency focused }\end{array}$ & Environmental, economic, + social focus \\
\hline
\end{tabular}

Source: own compilation

\section{Decentralization and Industrial Ecology}

Industrial ecology practices, especially those formulated spontaneously can be considered as decentralised circular economy initiatives. Therefore, lessons learnt about decentralization from public administration policy and governance may be relevant for investigating the relationship of the two, as well as the usefulness of IE in modelling CE, providing some further information.

Most literature on this broad issue in public policy theory focuses on two aspects: decentralisation and efficiency as well as decentralisation supporting the better understanding and fulfilment of local needs (Illés, 2008). When overviewing the benefits of decentralisation, Begg et al. mention the availability of more information, the measurability of impacts of decisions, easier adaptation to local circumstances and from the aspect of citizens, more controllability (Begg et al., 1993). These benefits are relevant for industrial ecology, with the modification that citizens in this context mean participants, primarily participating companies. Additionally, with fast technological progress, the availability of specific information is gaining more and more importance, making decentralisation even more important in case of technological, industrial processes, including IE practices. Begg at al. also give a comprehensive overview of the benefits of centralization which are: increased efficiency, economies of scale, elimination of negative spill-overs, more transparency, more capability to react on shocks, the decision-making process is more transparent, more equity, as well as more opportunities to reduce income differences e.g. by income transfers. In the context of circular economy, the latter, (socio)political aspects are not really relevant, however, efficiency issues are important: in a more centralised system, efficiency may be improved, compared to high independence of individual industrial ecosystems, focusing only on their own interest. Other authors also mention that in a decentralised system less specific knowledge is needed but the availability of less (specialised) experts may limit the opportunities (Illés, 2008). This is true for industrial ecology, too, if the local engineers and managers are only familiar with the sector they operate in or the specific technology they use, the potential for innovative, new solutions is more limited.

Stöhr emphasizes that centralization and decentralization are complements rather than 
alternatives to each other (Stöhr, 2001). In our view, this complementary relationship is highly relevant for the relationship of industrial ecology and circular economy, too, since top-down circular economy attempts have the potential to motivate and strengthen bottom-up industrial ecology solutions, reduce negative spill-overs and on the other hand, circular economy cannot be realised without the commitment of companies, specialised in certain sectors and engaged in micro-level cooperations. Thus, we can conclude, that some main findings of decentralization are useful and relevant to understand the relationship of IE and CE.

\section{Locational Aspects of Industrial Ecology}

As proximity is an important factor in location decisions, especially when targeting to close material flows and maximising energy efficiency, it is a logical consequence that geographically compact production sites are gaining growing attention. In this section we consider the location aspects of IE.

The systematic analyses of local and regional eco-industrial parks has become one of the central themes of IE literature by the early 2000s (Korhonen et al., 2004). Recent research on practice in various countries has been focusing on industrial parks or similar facilities that integrate some environmental or circular economy principles.

The International Framework for Eco-Industrial Parks was issued in cooperation of the United Nations Industrial Development Organization (UNIDO), the World Bank Group, and the German Development Cooperation (GIZ) GmbH in 2017. The purpose of the publication is to serve as a guide for policy-makers, as it was realised that industrial parks - in parallel with the targeted benefits - may cause some concentrated negative environmental as well as social impacts. The authors emphasize that several definitions and terminologies are available to describe eco-industrial parks, and choose Lowe's definition, that is applied by many international organisations: "A community of manufacturing and service businesses located together on a common property. Member businesses seek enhanced environmental, economic, and social performance through collaboration in managing environmental and resource issues." (Lowe, 1997 in World Bank Group, 2017, p. 21.)

The environmental nature can be described as "eco", "sustainable", "low carbon" "green" or "circular", the territory can be called "park", "zone", "area" or "estate" and the types of activities can be referred to as "industrial", "(special) economic", "technological", "investment" or "manufacturing".

Furthermore, the study published by the Swiss Federal Office for the Environment, focusing on the spatial aspects of eco-innovation, distinguishes "purely industrial" and "mixed urban and industrial areas" (Massard et al., 2014), increasing the abundance of terms further. Best practices and success factors are analysed for 168 sites labelled as "eco-innovation parks" from 27 countries. The main territorial focus is Europe (116 sites), but cases for nine other countries are also presented. Eco-criteria (what makes an industrial park "ecological" or "green") and success factors are identified. The sample size was big enough to formulate some general conclusions.

Table 2 summarises the diversity of terminology used to describe territories with some production activities targeting sustainability or the minimisation of negative 
environmental impacts. (Italics meaning that geographical proximity is not necessarily expected.)

Table 2: The diversity of terms describing sites

\begin{tabular}{|c|c|c|}
\hline Adjective & Description of main function & Name of the territory \\
\hline Eco & Industrial & Park \\
\hline Sustainable & (Special) Economic & Zone \\
\hline Low Carbon & Technological & Area \\
\hline Green & Investment & Cluster \\
\hline \multirow{2}{*}{ Circular } & Manufacturing & Estate \\
$\ldots$ & $\ldots$ & Network \\
\cline { 2 - 3 } & $\ldots$ & District \\
\cline { 2 - 3 } & Eco-innovation & Quarter \\
\hline
\end{tabular}

Source: own based on International Framework for Eco-Industrial Parks p. 21.

Geographic concentration thus has both negative and positive aspects, and also implies regional development issues. The Nordic Center for Spatial Development Nordic Center for Spatial Development, 2015) comes to the conclusion that industrial symbiosis plays a central role in "fostering green growth" by enabling the utilisation of formerly unused industrial flows in innovative ways, potentially by new, innovation-focused businesses. Their analysis concentrates on the regional development aspects of industrial symbiosis and reveals several potential benefits.

The UK National Industrial Symbiosis Program is a great example of a top-down initiatives to foster industrial ecology. Mirata (2004), based on early experience of three regional industrial symbiosis programmes in the UK emphasises the crucial role of a coordinating body and the diversity of individual cases. Paquin and Howard-Grenville (2012) gives a detailed analytical description of the evolution of this program, focusing on a relatively long eight-year-long period. This initiative clearly demonstrates the opportunities of overcoming limitations from decentralization, discussed earlier. The regional focus enabled cooperation among companies operating in various sectors located relatively close to each other, thus enabling reduction of logistical challenges and transportation costs as well as limited environmental externalities from transportation (Paquin \& Howard-Grenville, 2012).

We can conclude that research related to locational aspects has mostly been focused on micro-level and regional level, more macro-level analysis can be expected with the growing importance of circular economy.

\section{Flue Gas Desulfurization Gypsum}

After overviewing the relationship of industrial ecology and circular economy and the locational aspects of IE, in this section we investigate one of the technologies that enables the practical implementation of IE. The technology selected for a detailed analysis is the production of flue gas desulfurization (FGD) gypsum. This technology was developed for a traditional electricity generating technology - fossil fuel power plants - in order to minimize air pollution. 
Limestone based scrubbing processes have become the most popular of the flue gas desulphurisation processes (Eurogypsum, 2015). In 2006, 14.8 millions of tonnes of FGD gypsum were produced in total, in 18 countries (Ezrogypsum, 2015).

The technology and the by-product are special from multiple aspects:

- The technology was developed as the result of classical emission regulation, as a traditional end-of-pipe technology, its industrial ecology relevance is a "coincidence". Thus its environmental sustainability relevance is twofold: emission minimization and utilization of a by-product.

- The quality of the by-product is high and stable, therefore it was possible to develop a quality standard specifically for this type of production. FGD gypsum is a full value substitute for gypsum from mining.

- The product is typically cheaper than gypsum from mining. As the availability of mined gypsum is decreasing and the marginal cost is increasing the price difference is growing, making the technology even more competitive.

- Using FGD gypsum is environmentally beneficial from multiple aspects. Lee et al. (2012) analyse the benefits of using FGD gypsum as a substitute for natural gypsum in wallboard production in the USA, based on life-cycle analysis, focusing on energy consumption, water use and greenhouse gas emission, demonstrating significant savings.

- Beside the many positive sustainability implications, the utilisation of the by-product is linked to burning fossil fuel, resulting a major contradiction. In an early critical review of the potentials of IE O'Rourke et al. (1996) raise the question "Can coal-fired power plants and oil refineries be part of an "optimized" industrial ecosystem?" and conclude that "Efforts to 'minimize' material throughput by designing processes around existing waste streams (or designing waste streams for specific process needs) may 'minimize' waste from the existing technological infrastructure at the cost of entrenching "suboptimal", dirty technologies and thereby impeding a transition to more sustainable industrial practice - the very goal that IE alleges to promote." (O'Rourke et al., 1996, p. 101-102). This argument is still relevant for this particular technology.

We can conclude that the technology is mature and that there are some contradictions, still it is reasonable to analyse it in detail to gain information potentially useful for the application of new, innovative solutions in similar settings.

\section{The Hungarian Fossil Fuel Power Plant Case Study}

\subsection{Development of the industrial park}

The Hungarian Mátra industrial park is located in Northern Hungary. The main employer (anchor tenant), the power plant started to operate in 1969 as Gagarin lignitefueled power plant, as a typical large-scale project of a planned economy. The industrial park developed gradually. Some by-product generated in the plant was used by the construction industry already before the production of gypsum started, therefore, the idea of large-scale utilisation of a by-product was not unknown for local actors. As EU emission standards had to be met, there were only two options: to shut down the power plant or to install some end-of-pipe technology to meet the new standards. The former owner decided on the latter, choosing intentionally a technology for flue gas desulfurization which is not the cheapest but enables selling the by-product, FGD 
gypsum for construction material producing companies.

\subsection{The relevance of eco-criteria}

In the next section we overview the relevance of eco-criteria identified by Massard, Jacquat and Zürcher (2014) for the Mátra industrial park. Although the park does not identify itself as an eco-innovation park, most criteria are met to some extent (Table 3). In 2012 the industrial park won the competitiveness award for Hungarian industrial parks, and one of the key success factors was meeting some eco-criteria. (Similar initiatives may enhance the cohesion among local companies, although the likely limitation is the temporary nature of this improvement.)

Energy efficiency is one of the most important aspects, as the main profile of the park is the generation of electricity by a traditional thermal power plant which means the generation of an enormous amount of heat as well. As a consequence, several nearby companies use cheap steam and electricity, involving a biodiesel plant. This latter is not the only renewable energy technology in the park, two PV farms have also been built as brownfield developments.

Waste management is clearly important, as even with closing some material flows, waste cannot completely be eliminated during the production processes. The situation is special in case of this IP, as companies do not cooperate in this regard, but some communal waste is burnt at the power plant, enabling energetic utilization and creating some connection with nearby settlements. (This is clearly not enough to consider the area as a "mixed urban and industrial area", but can be seen as a small step towards that direction.)

Water management is not a priority, however, communal waste water of the companies is treated in the facility of the PP.

Material or chemical flows are of special importance. The empiric study described in the following section focuses on this issue, namely the experiences from using FGD gypsum by construction sector companies.

Biodiversity and land use are crucial issues, because of the open-cast mining activities. A huge territory has been involved during several decades of operation. Mines have been technically and biologically recultivated. Successful recultivation is demonstrated by the fact that a nature-trail has been established on the recultivated area. The importance of nature conservation is high since the industrial park is located in one of the few mountainous regions of the country.

Mobility and transportation is not among the priorities, individual companies have contracts with the local public transportation company.

Air pollution prevention is very relevant, too - as it was described above - the desulfurisation unit was basically installed for this purpose.

Noise prevention is especially important for the mining activity, especially close to settlements, the measures applied are the operation of modern mining machines and extensive tree planting.

Environmental management is strengthened by the implementation of ISO 14001 standard by the power plant. Other companies in the park are not required to implement similar management systems, but the power plant expects high environmental performance from its partners. 
Regarding the social issues the power plant fosters equal opportunities and its sponsorship activity is also strong.

Table 3 summarises the relevance of eco-criteria in case of this industrial park. We can conclude, that most issues are treated on the company level, but there is some cooperation among companies that can contribute to the improvement of the sustainability performance of the industrial park.

Table 3: The relevance of eco-criteria in case of the industrial park

\begin{tabular}{|l|l|}
\hline ECO-criteria & Relevance in case of Mátra industrial park \\
\hline Energy efficiency & $\begin{array}{l}\text { Several companies use cheap steam, electricity (e.g. } \\
\text { biodiesel plant) }\end{array}$ \\
\hline Renewable energy sources & Photovoltaic power plant, biodiesel plant \\
\hline Waste management & Burn some communal \\
\hline Water management & Communal: PP \\
\hline Material/ chemical flow & Gypsum \\
\hline Biodiversity & Recultivation after mining, nature-trail \\
\hline Mobility, transportation & Individual contracts with bus company Volán \\
\hline Land use & Continuous technical and biological recultivation of mines \\
\hline Air pollution prevention & End-of-pipe + fuel optimisation \\
\hline Noise prevention & Modern mining machines, tree planting \\
\hline $\begin{array}{l}\text { Environmental } \\
\text { systems }\end{array}$ & $\begin{array}{l}\text { Power plant: ISO14001, high performance expected from } \\
\text { partners }\end{array}$ \\
\hline Cultural, social, health and safety & Equal opportunities, sport sponsorship... \\
\hline
\end{tabular}

Source: own compilation

When considering the criteria listed it was found that even for an industrial park which does not denote itself as an eco-innovation park, most criteria are relevant and basically met. Since most industrial production is realised in traditional industrial parks, and "IP development remains the mainstream industrial agglomeration model and has not yet experienced a transition into EIP development" (Susur et al., 2019, p. 338) it is very important to improve the sustainability performance of all IPs. On one hand this is positive and desirable: industrial production should integrate eco-innovation or IE principles as broadly as possible. However, on the other hand, we can conclude that the distinction of eco-industrial or eco-innovation parks is not unequivocal, having both positive and potentially harmful consequences: It is relatively easy to meet the criteria in case of a positive attitude and real commitment, but also to position an industrial park as an eco-industrial one without any real attempt and fundamental change of operation, i.e. the opportunity of green-washing is relatively high.

Proximity is an important factor for eco-industrial parks basically because of energy efficiency. In this case, traditional location theory considerations also make it sensible to locate the activities in close proximity to each other: the high weight and transportation cost of the input for construction material producing companies.

It is a problem if an industrial ecology practice is used in case of traditional technologies, close to the end of the life cycle of a technology. In extreme cases it can contribute to the application of otherwise outdated technologies by improving their efficiency (or reducing environmental externalities to an acceptable level) and making them temporarily 
competitive. Efforts to minimize material throughputs by developing processes based on existing waste streams can reduce the motivation to find more sustainable, innovative technologies, causing so-called "technological lock-ins" (O’Rourke et al. 1996). (Interestingly, the same phrase, "lock-in" - independently - is used in regional development literature one decade later, with similar meaning, indicating the danger of excessive sectoral specialization of a region leading to difficulties when trying to diversify its economic activities (Boschma, 2005).)

\subsection{Experience of gypsum buyers}

In order to understand industrial symbiosis from the point of view of participating companies, semi-structured interviews have been conducted with managers of three construction material producers, all of them using FGD gypsum produced as a by-product at the power plant, as an important raw material. The interview addressed the following issues: origin of the idea of IS and motivating factors, development of IS, challenges caused by using a by-product as input (e.g. quality management problems), unsuccessful IS or related innovation attempts, unexpected benefits, risk factors and risk management attempts, success factors and benefits, potential further cooperation, expectations regarding industrial park services and opinion about the relationship of innovation and IS as well as potentials of IS in general.

Based on the interviews we have found that the main motivating factor for applying an industrial ecology practice was clearly economic for all actors. The power plant realises additional income from selling the by-product, although its minor share in its total income was emphasised by the representative of the company. On the other hand, the construction material producers settled here in order to buy cheap gypsum as an essential input for their production, and they do not have alternative sourcing options. Since the management of the industrial park is provided by the power plant - as the main producer and employer - the dependency of the other actors is high. None of the interviewers stated that they detected any consumer demand for environmentally friendly products. One mentioned that they do not even communicate to their consumers that they use a by-product for production. However, when applying for an eco-label, it was a benefit for them.

Among the success factors, all interviewees mentioned communication and some highlighted the importance of good personal relationships. The companies communicate on a regular basis with each other, there is daily communication between production managers, weekly communication between middle managers and semi-annual communication between top managers. One of the respondents mentioned, that although communication regarding operational issues is simple, it is more difficult to agree on strategic issues (e.g. significant change of volume bought) with the large company (the PP). The most significant improvement, mentioned by one of the construction sector companies was also associated with communication. They revealed that while earlier the power plant did not warn the buyers about potential quality problems, now they always share this type of information with them. These findings are in harmony with those of Ashton on the importance of trust for IS development (Ashton, 2008).

The most important challenge is that gypsum is a by-product and it is "not a central 
issue" for the producer to monitor and control its quality. At the beginnings the constructor companies intended to control the process (e.g. to add some additives), but they could not agree on who should bear its costs, and therefore it was not realised. One of the construction sector companies mentioned a technological challenge, too. The moisture content of FGD gypsum is high, therefore, they had to develop a special feeder in order to be able to use it for their technology. This is a simple example on how IE may contribute to innovation.

The most important risk mentioned by all three construction material producing companies was the temporary deficit of gypsum production. Storing gypsum is therefore an integral part of their risk management strategy.

Companies have not mentioned any significant change in the regulatory environment and they do not perceive EU circular economy attempts. One of the experts mentioned that the adaptation of EU energy efficiency initiatives in Hungary was not optimal: in his opinion, the compulsory energy audit required from large companies is rather a formal procedure than a real measure to improve energy efficiency. Several interviewees would welcome tenders - especially with simple procedures - to be able to further improve their environmental performance.

None of the respondents had any expectations to extend the cooperation among companies to further areas. However, they agreed that the current cooperation could be further improved, e.g. to a "less asymmetric" relationship with the power plant. This finding suggests that participation in IE solutions does not necessarily motivate companies to look for further opportunities to close material flows or improve their resource or energy efficiency.

One of the construction sector companies assessed the feasibility of a photovoltaic (PV) system and concluded that - since they buy cheap electricity directly from the producer PV is not a recoverable investment for them. This simple example clearly demonstrates the problem of the optimisation level. This example also demonstrated that in a much more complex system the consequences of inter-connections may result unforeseeable decisions by individual profit-maximizing actors, not always in harmony with system or macro level sustainability.

Respondents had various opinions on the relationship of industrial symbiosis and innovation. Some see a positive relationship, while some believe that innovation is limited as a consequence of IS, in this specific case, because the quality of the gypsum has to be stable. The power plant cannot change, develop the technology for its own interest, and, since there are several buyers of the gypsum, the technology cannot be improved for the benefit of one of the customers either. In his opinion IS is clearly a limiting factor for innovation. They did not agree on the potentials of IS in general, some said that IS can only be applied for some special by-products, while others think that there are several opportunities for various technologies.

We can conclude that participation in a traditional industrial symbiosis does not necessarily support environmental innovation and does not motivate participants to try to establish further cooperations. Earlier studies also revealed that existing successful cooperation does not always lead to further synergies, as IS development may face various obstacles (Chertow 2007; Lombardi \& Laybourn, 2012). It is also an important finding of the interviews that similar companies may have different experiences and 
views on the same issues.

\section{Discussion}

In-depth case studies can provide useful information for further improving industrial ecology practices, what is crucial for the realisation of circular economy attempts. They can reveal potential sources of inefficiency, conflicts of interest as well as potential solutions, best practices. Therefore it would be desirable to establish more platforms for discussing such issues among practitioners. The Hungarian case study pointed out that although the technology is used in several countries there is limited communication with actors of similar industrial eco-systems, which could increase efficiency. Sharing information by practitioners would enable the identification and categorisation of typical challenges and solution options. This could also shorten the learning phase by helping companies to improve the efficiency of the system more quickly. Industrial ecology attempts cannot be treated as isolated systems. Closing material cycles is desirable, but information flows should be extended in parallel in order to help knowledge and technology transfer. Special attention is needed, since a relatively closed, semi-self-sustaining system can easily become isolated.

The concentrated location and inter-dependence of producers is reasonable and desirable from the aspect of economic and eco-efficiency (e.g. decreasing transportation costs and externalities), however may imply geographically concentrated problems as well, for example in case of a recession period. If the production of main actors decrease, those, using the by-products either are forced to reduce their production too - even if the demand for their products is stable or growing - or have to look for alternative input sources (temporarily, making it even more difficult). In case of the Hungarian industrial park presented, the most important risk mentioned by the construction material producing companies was the temporary deficit of gypsum production. Storing gypsum is therefore an integral part of their risk management strategy, however, storing is not an option in case of several other by-products.

In the Hungarian case, companies using the gypsum have no alternative scenarios for buying this important input after the power plant is closed. Since they are subsidiaries of multinationals, their long-term sourcing strategies presumably mostly neglect regional development issues. Therefore, authorities dealing with regional development should consider these issues when formulating regional development strategies.

Even in case of relatively low number of actors the network of interests may be complicated. In order to increase system efficiency, especially with actors of different size and power, an independent management agent - taking into consideration the interests and opportunities of all actors - is highly desirable. In cases analysed earlier, a coordinating body is frequently established to help companies' cooperation and to develop a common vision or strategy (Boons et al. 2011; Paquin \& Howard-Grenville, 2012).

Some tendencies in technological development increase the opportunities of industrial ecology while others deteriorate it: The availability of more and more information on production processes increases measurement and control options of interim and byproducts. It enables intervening in the processes more complexly and precisely, enabling 
changing not only the quality/quantity of end-products but also that of the by-products. This may increase customer expectations (such as in case of our case study) but also extend the "playing field", that is the opportunities to meet those. That is, the optimisation opportunities and challenges can be expected to increase.

The increasing number of chemicals and materials broaden the opportunities on the one hand but on the other hand will make it very challenging to close every material cycle, the latter effect being more dominant. Recognizing this problem, some definitions of circular economy mention that the concept "eliminates the use of toxic chemicals, which impair reuse" (Ellen McArthur Foundation, 2012, p. 7), however it is challenging to be implemented and not only toxic chemicals are problematic from the aspect of closing the material cycles. This phenomenon indicates the different role of diversity in ecosystems and economic production-consumption systems. In case of the former, diversity is clearly desirable to be preserved - according to Perrings (Perrings, 1991) the main consequence of decreasing biodiversity is decreasing resilience. On the other hand, in the artificially managed economic production-consumption systems growing diversity will imply more difficulties in understanding, tracking and closing the material flows. Renewable-based production processes should be preferred because of long-term sustainability and also the applicability of ecosystem services for waste absorption.

As learnt from the Hungarian case study, economic considerations are especially important, therefore, economic incentives are needed but should be complemented by additional measures.

The complex vision of circular economy cannot be realised without understanding already accumulated but scattered information on industrial ecology practices. Therefore, further detailed analysis of existing IE practices - considering social and economic issues as well as understanding individual participants' interests, experiences, and views - is highly desirable.

\section{References}

Allenby, B. (1998). Earth systems engineering: the role of industrial ecology in an engineered world. Journal of Industrial Ecology, 2(3), 73-93.

Allenby, B. (2004). Clean production in context: an information infrastructure perspective. Lournal of Cleaner Production, 12 (8-10), 833-839.

Ashton, W. (2008). Understanding the organization of industrial ecosystems: A social network approach. Journal of Industrial Ecology, 12(1), 34-51.

Begg, D., Crémer, J., Danthine, J-P., Edwards, J., Grilli, V., Neven, D., Seabright, P. , Sinn, H-V., Venables, A., Wyplosz, C. (1993). Making Sense of Subsidiarity: How Much Centralization for Europe? Monitoring European Integration, Vol 4. London. Centre for Economic Policy Research

Boons, F., Spekkink, W., and Mouzakitis, Y. (2011). Thedynamics of industrial symbiosis: a proposal for a conceptual framework based upon a comprehensive literature review. Journal of Cleaner Production, 19 (9-10), 905-911.

Boschma, R. (2005). Proximity and Innovation: A Critical Assessment. Regional Studies, 39,1, 61-74.

Chertow, M. R. (2007). “Uncovering” Industrial Symbiosis. Journal of Industrial Ecology, 11 (1), 11-30.

Ellen MacArthur Foundation (2012): Towards the Circular Economy: Economic and Business Rationale for an Accelerated Transition. Available at https://www.ellenmacarthurfoundation.org/assets /downloads/publications/Ellen-MacArthur-Foundation-Towards-the-Circular-Economy-vol.1.pdf 
EU (2013). Decision No 1386/2013/EU of the European Parliament and of the Council of 20 November 2013 on a General Union Environment Action Programme to 2020 'Living well, within the limits of our planet'. Text with EEA Relevance.

European Commission (2011). Roadmap to a Resource Efficient Europe. Communication COM(2011) 571. Available at: http://ec.europa.eu/environment/resource_efficiency/about/roadmap/index_en.htm

European Commission (2014). Towards a circular economy: A zero waste programme for Europe. Available at: http://eurlex.europa.eu/resource.html?uri=cellar:50edd1fd-01ec-11e4-831f-01aa75ed71a1.0001.01 /DOC_1\&format=PDF

Eurogypsum (2015). Living with Gypsum: From Raw Material to Finished Products. Available at: http://www.eurogypsum.org/wp-content/uploads/2015/04/livingwithgypsum.pdf

Frosch, R. A., Gallopoulos, N. E. (1989). Strategies for Manufacturing. Scientific American, 261 (3), 144-152.

Illés, I. (2008). Regionális gazdaságtan - Területfejlesztés. (Regional economics - spatial development) (in Hungarian). Typotext, Budapest.

Korhonen, J. (2005). Theory of industrial ecology: the case of the concept of diversity. Progress in Industrial Ecology - An International Journal, 2 (1), 35-72.

Korhonen, J., Huisingh, Chiu, A.S.F (2004). Applications of industrial ecology - an overview of the special issue. Journal of Cleaner Production, 12, 803-807.

Lee, J. C., Bradshaw, S. L., Edil, T. B., Benson, C .H. (2012). Quantifying the Benefits of Using Flue Gas Desulfurization Gypsum in Sustainable Wallboard Production, Coal Combustion and Gasification Products, 4, 17-20.

Lombardi, R., Laybourn, P. (2012) Redefi ning Industrial Symbiosis. Crossing Academic-Practitioner Boundaries. Journal of Industrial Ecology, 16 (1), 28-37.

Lowe, E. A., Evans, L. K. (1995). Industrial ecology and industrial ecosystems. Journal of Cleaner Production, $\underline{3}$ (1-2), 47-53.

Lowe, E. A. (1997). Eco-Industrial Parks: A Handbook. Manila, Philippines: Asian Development Bank.

Massard G., Jacquat O., Zürcher D. (2014). International survey on ecoinnovation parks. Learning from experiences on the spatial dimension of eco-innovation. Federal Office for the Environment and the ERANET. ECO-INNOVERA, Bern. Environmental studies no. 1402: 310 pp.

Mirata, M. (2004). Experiences from early stages of a national industrial symbiosis programme in the UK: determinants and coordination challenges. Journal of Cleaner Production, 12, 8-10, 967-983.

Nordic Center for Spatial Development (2015). The potential of industrial symbiosis as a key driver of green growth in Nordic regions. ISBN 978-91-87295-34-8

O’Rourke, D., Connelly, L., Koshland C. (1996). Industrial ecology: a critical review. International Journal of Environment and Pollution, 6 (2-3), 89-112.

Paquin, R., Howard-Grenville, J. (2012): The evolution of facilitated industrial symbiosis. Journal of Industrial Ecology, 16 (1), 83-93.

Perrings, C. (1991). „Reserved Rationality and the Precautionary Principle: Technological Change, Time and Uncertainty in Environmental Decision Making" in R. Costanza (ed.), Ecological Economics: The Science and Management of Sustainability, Columbia University Press, New York

Renner, G.T. (1947). Geography of Industrial Localization. Economic Geography. 23 (3), 167-189.

Stöhr, W.B. (2001). Subsidiarity: A Key Concept for Regional Development Policy. In Stöhr, W.B. et al. (eds.) New Regional Development Paradigms. Volume 3: Decentralization, Governance, and the New Planning for Local-Level Development. Greenwood Press, London. 35-51.

Susur, E., Hidalgo, A., \& Chiaroni, D. (2019). A strategic niche management perspective on transitions to eco-industrial park development: A systematic review of case studies. Resources, Conservation and Recycling, 140, 338-359.

World Bank Group (2017). An International Framework For Eco-Industrial Parks.

Yang, P.P., Lay, O.B. (2004). Applying ecosystem concepts to the planning of industrial areas: a case study of Singapore's Jurong Island. Journal of Cleaner Production. 12, 8-10, 1011-1023. 